\title{
Analysis on the Limiting Factors of Achieving the Mission of State-Owned Enterprises Based on Baosteel
}

\author{
Yudeng $\mathrm{Xu}^{1, *}$ Zhiqian Zeng ${ }^{2}$
}

\author{
${ }^{1}$ Accounting, Jilin University of Finance and Economics \\ 2 Accounting, Jilin University of Finance and Economics \\ *Corresponding author. Email:1929596840@qq.com
}

\begin{abstract}
As an important part of China's economy, compared with ordinary enterprises, state-owned enterprises bear more social responsibilities, so there are more factors restricting their development. Recently, domestic economic development has been slowed down and quality has been improved. Pollution prevention and control efforts have been increasing. The fight against poverty has entered a decisive stage. Foreign COVID-19 continues to wreak havoc and frequent wars. Complex social environment tests state-owned enterprises. From the perspective of corporate strategy, this paper compares Baosteel with Ansteel and Capitalsteel to explore how Baosteel can break through its own constraints and realize its mission through strategic planning, so as to provide reference for the development of other state-owned enterprises.
\end{abstract}

Keywords: strategic management, enterprise mission, steel industry, SWOT analysis

\section{COMPANY PROFILE}

Baoshan Iron Steel Co (hereinafter referred to as Baosteel) was established in 2000 and has been listed as one of the world's top 500 enterprises for 16 consecutive years, ranking No. 149. Its output of oriented electrical steel ranked the first in the world, and the output of crude steel ranked the second in the world. It is a typical representative of the modern steel industry. In 2017, Baosteel and WISCO were merged, and the market share was further expanded. Baosteel, with the mission of "being a demonstrator of high-quality development of the steel industry and a leader of future steel industry", adheres to green transformation, attaches great importance to innovative development, cultivates its core competitiveness, and promotes its steady development in a complex external environment, becoming the leader of the steel industry in China.

\section{ANALYSIS OF EXTERNAL ENVIRONMENT}

\subsection{Macro environment analysis - PESTEL model}

Politics: 2020 is the year when China will complete the building of a well-off society in an all-round way and the 13th five year plan will come to an end, and the tax reduction and fee reduction policies of enterprises will be further promoted. In 2020, the central government will make a deployment to accelerate the progress of new infrastructure construction, which will lead to a wave of "new infrastructure" in the market.

Economy: In recent years, protectionism and unilateralism have been on the rise, economic globalization has encountered twists and turns, and unstable and uncertain factors are large. Steel enterprises are facing more and more international trade disputes. In the first half of 2020, affected by the COVID-19 epidemic, the global economic environment will worsen, but the basic trend of domestic economy to stabilize and improve has not changed. 
Society: China has basically built a well-off society. People's living standards have been greatly improved. The pattern of interests has become more complex. Social needs have become hierarchical and mass. People have begun to pursue personalized and brand based consumption. However, there is also the problem of aging population.

Science and technology: Chinese R\&D expenditure has been increasing steadily, ranking No. 2 in the world. However, there is still a large gap between Chinese R\&D expenditure and the United States, Japan and other world science and technology powers. Basic research, the proportion of government funds is relatively low and other problems are prominent. Big data and artificial intelligence technologies have been widely applied, and new material technology has developed rapidly. At the National People's Congress, the Ministry of industry and information technology proposed to support the development of new steel materials from various aspects, which is a great signal for research.

Environmental protection and laws: the new environmental protection law and new pollutant emission standards are implemented, and Chinese environmental protection supervision is continuously strengthened to strictly control carbon emissions; the production safety law and the safety management law of hazardous chemicals are about to be implemented, and the government has been increasing the supervision and punishment of enterprise safety production and occupational health. ${ }^{[1]}$

\subsection{Industry analysis}

\subsubsection{Industry status analysis}

In 2018, Chinese steel industry began to decline after the steel industry benefited from the combined effect of supply side structural adjustment, industrial green upgrading, strong market demand and other factors, and the economic benefits reached the historical best level.

In 2019 and the first half of 2020, the output of pig iron, crude steel and steel in China has repeatedly reached a record high, of which, the year-on-year growth in 2019 was $5.3 \%, 8.3 \%$ and $9.8 \%$ respectively, and the growth in the first half of 2020 was $2.2 \%, 1.4 \%$ and $2.7 \%$ respectively. However, behind the high growth of production is the backlog of steel inventory, the decline in both import and export of steel and the significant decline in the economic benefits of steel enterprises. The reason for this is that Chinese economy is in the transition from high-speed growth to high-quality development stage, economic growth slows down, and the demand for steel in domestic downstream industries such as automobiles, household appliances and real estate decreases, which affects the year-on-year decline in steel prices. At the same time, the price of raw materials rose significantly, which has a greater impact on the profit of downstream steel manufacturing industry.

In the first half of 2020, in addition to the impact of the above factors, the outbreak of new crown pneumonia has significantly reduced the short-term demand, coupled with the continuous rise in iron ore import prices, the short-term profits of steel enterprises have been significantly reduced. However, with the effective control of the domestic epidemic, the full resumption of production by enterprises and the implementation of the central infrastructure support policy, the steel consumption has returned to normal level and gradually increased, the daily steel production and steel prices of steel enterprises have bottomed out and rebounded, and the domestic steel market has basically returned to normal.

\subsubsection{Industry development trend}

In terms of domestic market, the effect of the national "six-phase stability" and "six-phase guarantee" policies and measures to hedge the impact of the epidemic has gradually emerged, the domestic economy has recovered and the operation situation has continued to improve, the supply and demand of the manufacturing industry has continued to recover, the demand for steel has increased significantly, and steel enterprises have ushered in a rare period of market opportunities. However, with the increasing restriction of environmental protection policies and regulations, the risk of rising environmental protection costs has become the focus of attention. The ultra-low emission transformation and capacity replacement projects in the steel industry continue to be promoted. The replacement capacity projects will be put into operation in a centralized manner, bringing supply pressure to the market. The steel price will show a downward trend of fluctuations, which will lead to the continuous reduction of profits of steel enterprises and the increasingly fierce competition in the domestic market.

In terms of overseas markets, with the rapid spread of the epidemic, the global economy has fallen into a deep recession, and major steel producing countries have reduced their production. However, as China recovered from the epidemic earlier, Chinese steel enterprises have been able to continuously increase production and take the lead in occupying overseas markets. In this regard, countries may strengthen protectionist measures, so that economic globalization will encounter a headwind. If the foreign epidemic is not effectively controlled, the international steel market may face greater turbulence. [1][3] 


\subsection{Analysis on the source of competitiveness}

\subsubsection{Competitors}

In the ranking of revenue of Companies in the metal industry in 2019, Baosteel Group ranked first, with revenue far exceeding the second by nearly 100 billion yuan. Its $\mathrm{R} \& \mathrm{D}$ investment is also far ahead of its competitors in the same industry, and there are few domestic steel enterprises that can compete with it. As a result, Baosteel's main competitors are from overseas, especially Japanese and Korean steel enterprises with strong scientific and technological innovation capabilities, both in terms of steel output and the company's net profit.

\subsubsection{Power of the buyer}

Baosteel has a domestic share of $100 \%$ in the D.C. UHV market of oriented silicon steel, which has monopolized the domestic market and maintained a market share of more than $50 \%$ for cold-rolled automobile plates. Baosteel is an industry giant. Domestic purchasers have few alternative sources of supply and weak bargaining power. In addition, the amount of steel purchase orders is large, and purchasers suffer from high cost to replace suppliers. The strength of Baosteel compared with domestic purchasers Middle ranking.

\subsubsection{Power of suppliers}

Baosteel's iron ore supply is almost entirely dependent on foreign imports. In 2018, foreign imports accounted for $99 \%$ of the supply. Affected by the settlement exchange rate, political and economic factors of various countries and the fluctuation of international iron ore market price, Baosteel does not have an advantage in the competition with suppliers.

\subsubsection{Threat of alternatives}

In recent years, new material technology and 3D printing technology have developed rapidly, occupying low-end markets such as bicycle manufacturing and highend markets such as aerospace. However, steel still occupies an absolute dominant position in such markets as automobile manufacturing and construction engineering. As new materials such as special metal functional materials and high-end metal structural materials belong to the scientific research scope of the steel industry, the threat of product substitution to Baosteel is not significant. On the contrary, the development of new material technology and Baosteel's high R \& D investment complement each other, helping Baosteel to develop new steel products to occupy the high-end product market. ${ }^{[3]}$

\subsubsection{Threat of entry}

As a capital intensive, resource intensive and technology intensive industry, the steel industry has high barriers to market entry. However, the increasingly stringent energy saving and emission reduction indicators make the steel technology barriers higher and higher, and the threat of potential entrants is small.

\section{INTERNAL ANALYSIS}

\subsection{Financial analysis}

\subsubsection{Solvency}

\subsubsection{Horizontal comparison}

The theoretical optimal ratio of current ratio is $2: 1$, and quick ratio the theoretical optimal ratio is $1: 1$. The current ratio and quick ratio reflect the short-term solvency of the enterprise. Compared with the two enterprises in the same industry, it is not difficult to see that Baosteel's current ratio and quick ratio are both ahead of its competitors, especially the quick ratio is much higher than that of Capital steel by nearly 0.5 . It can be inferred from the table that the implementation of the supply side reform of Baosteel to reduce production capacity and inventory is better than that two companies. ${ }^{[2]}$ Therefore, Baosteel's short-term debt paying ability is better than that of Ansteel and Capital steel, and it can make a better and faster response to changes in the external environment, and its market share ability is also better.

Asset liability ratio $=$ Total Liabilities $/$ total assets $\times$ $100 \%$, which generally reflects the debt status of the enterprise. The debt to asset ratio of Baosteel is far lower than that of Capital steel and slightly higher than that of Ansteel.

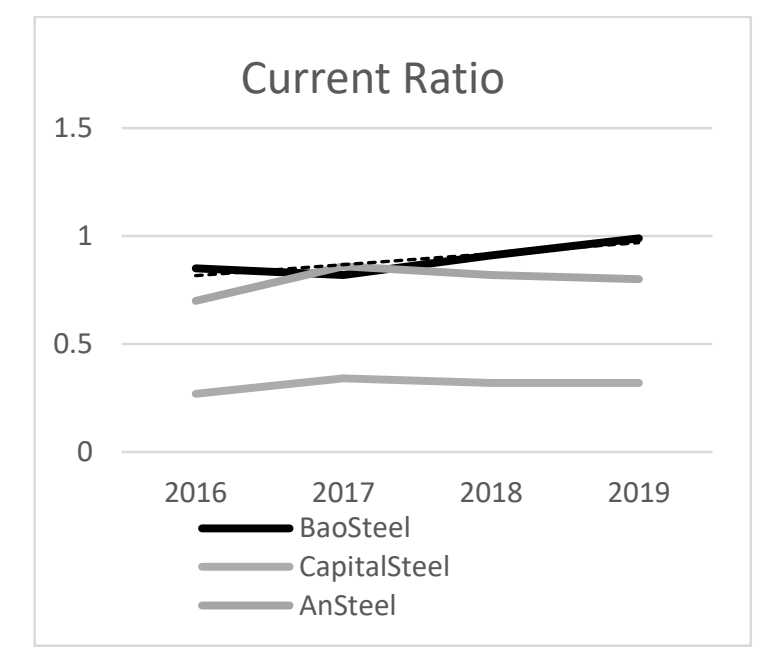




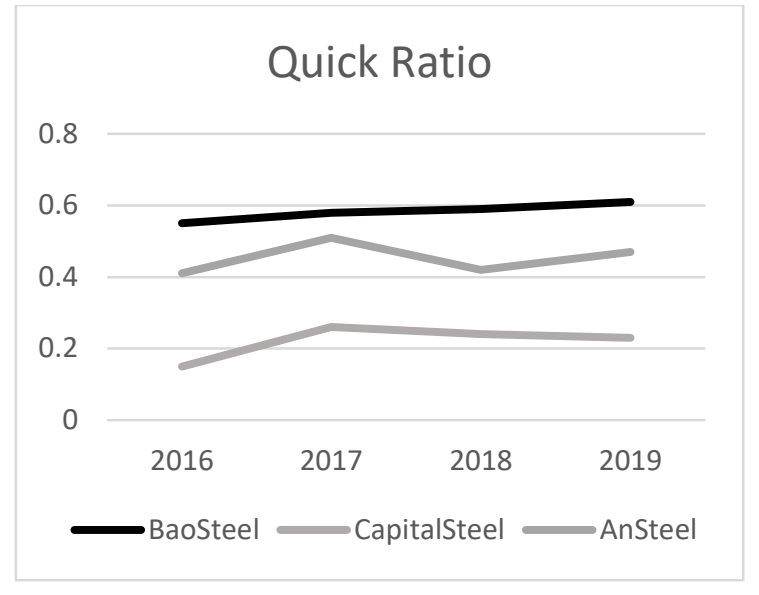

Figure 1 Solvency analysis

\subsubsection{Vertical comparison}

From 2016 to the first half of 2020, the current ratio and quick ratio of Baosteel increased steadily. In the first half of 2020, the quick ratio increased significantly by 0.13 compared with 2019 , thus driving the current ratio to increase by 0.5 , breaking through the threshold of 1 . It can be seen that the improvement of Baosteel's shortterm debt paying ability depends on the solid liquidation of inventory rather than the increase of receivables.

The asset liability ratio of Baosteel continued to decline from 2016 to 2018, and fluctuated in the first half of 2019 and 2020 due to the deterioration of external business environment and the COVID-19, but remained below $50 \%$ in general. Therefore, in general, Baosteel's debt position is stable and improving, with relatively small financial risks and strong long-term solvency and ability to continue to raise debt. ${ }^{[2]}$

Table 1. Solvency of Baosteel

\begin{tabular}{|c|c|c|c|c|}
\hline & 2019 & 2018 & 2017 & 2016 \\
\hline Current ratio & 0.99 & 0.91 & 0.82 & 0.85 \\
\hline Quick ratio & 0.61 & 0.59 & 0.58 & 0.55 \\
\hline $\begin{array}{c}\text { Asset liability } \\
\text { ratio(\%) }\end{array}$ & 43.70 & 43.53 & 50.18 & 50.96 \\
\hline
\end{tabular}

\subsubsection{Profitability}

Gross profit is used to measure the price reduction space of the enterprise's products; operating profit margin, which is an evaluation of the enterprise's management and operation ability.

The gross profit margin of Baosteel is similar to that of the other two enterprises, and the price reduction space is equivalent, so Baosteel is unable to occupy the market through the low-price strategy. However, Baosteel has led Capital steel and Baosteel in operating profit margin for many years. Therefore, the profitability of Baosteel's operating activities is better than the other two enterprises. [2]
Net profit margin $=$ net profit $/$ operating income $\times$ $100 \%$, reflecting the ability of the enterprise to generate profits from operating income and reflecting the level of senior management of the enterprise; return on total assets $=$ profit before interest and tax / average total assets, which is used to measure the quality of the assets available to the management of the enterprise. Overall, the net profit margin and return on total assets of Baosteel are better than those of Ansteel and Baosteel. The management of Baosteel has not only brought sufficient revenue to the enterprise, but also has been stabilizing the yield at a high level instead of fluctuating significantly like that of Ansteel. Especially when the overall net profit margin and return on total assets in the first half of 2019 and 2020 are lower, Baosteel can still take the lead in comparison with Ansteel and Capital steel, indicating that the management of Baosteel has strong control over the operation of the enterprise.

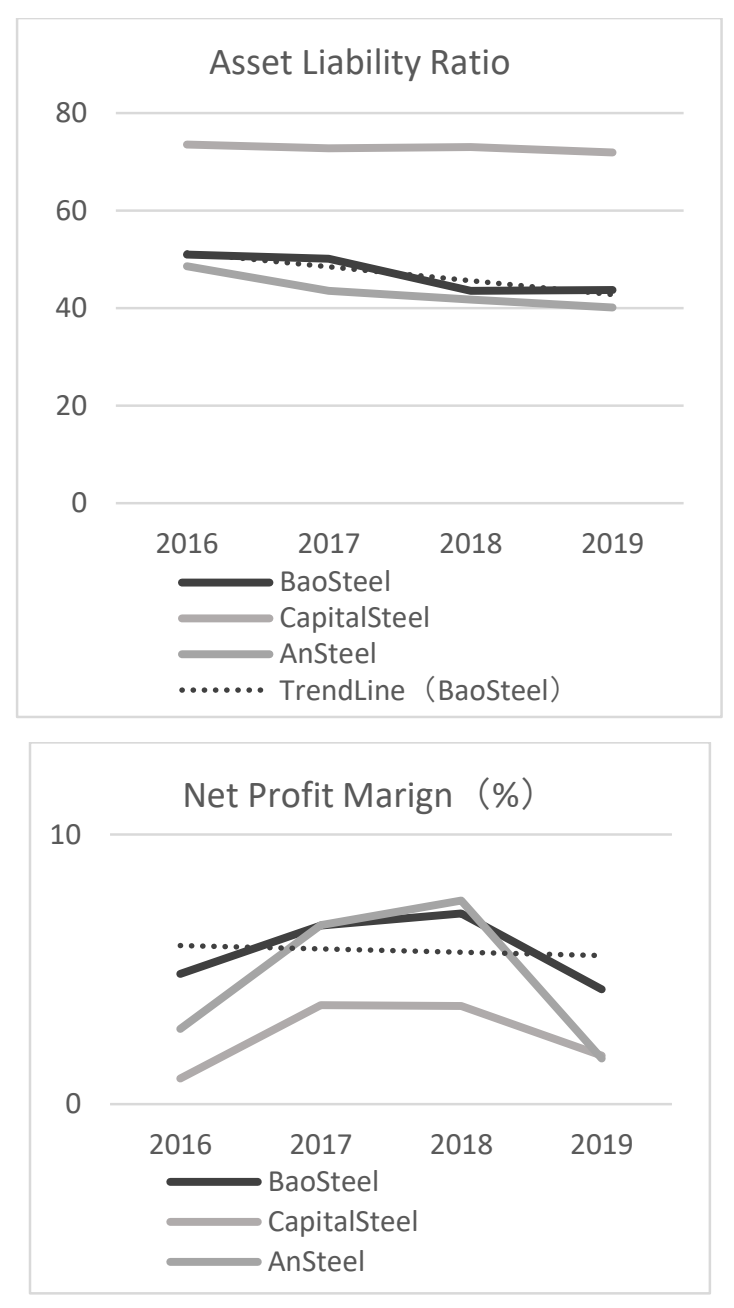




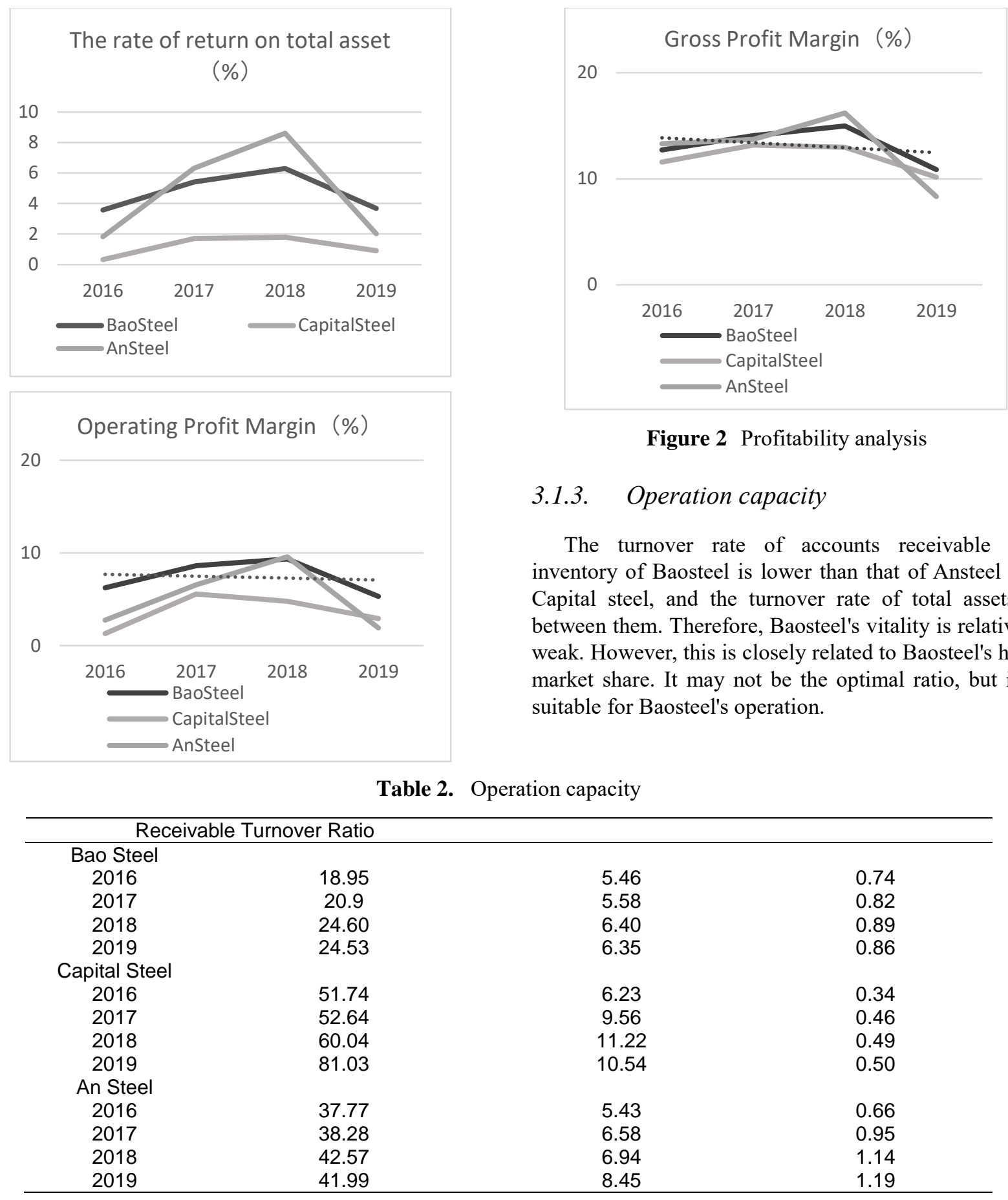

\subsubsection{ROE and ROIC}

Both ROE and ROIC of Baosteel are higher than those of Ansteel and Capital steel. Baosteel is a highprofile company with both ROE and ROIC. It has obvious advantages in the industry competition, high rate of return and strong gold absorption, which helps Baosteel absorb more capital in the capital market and widen the distance with competitors in the same industry.
Table 3. ROE \& ROIC

\begin{tabular}{ccc}
\hline & ROE & ROIC \\
\hline Bao Steel & & \\
2016 & 7.7 & 7 \\
2017 & 12.2 & 10 \\
2018 & 12.7 & 12 \\
2019 & 7.1 & 10 \\
Capital Steel & & \\
2016 & 3.7 & 4 \\
2017 & 11.8 & 15 \\
2018 & 14.8 & 9 \\
2019 & 3.4 & 4
\end{tabular}


An Steel

$\begin{array}{lll}2016 & 1.7 & 4 \\ 2017 & 8.7 & 5 \\ 2018 & 9.3 & 5 \\ 2019 & 4.8 & 2\end{array}$

\subsection{Analysis of core competence}

\subsubsection{Research and development investment analysis}

"Science and technology is the first productivity", and science and technology is the core ability for enterprises to survive and develop and participate in market competition. In recent years, the number of invention patents of Baosteel has been increasing year by year, and the investment rate of R\&D has been increasing. ${ }^{[3]}$

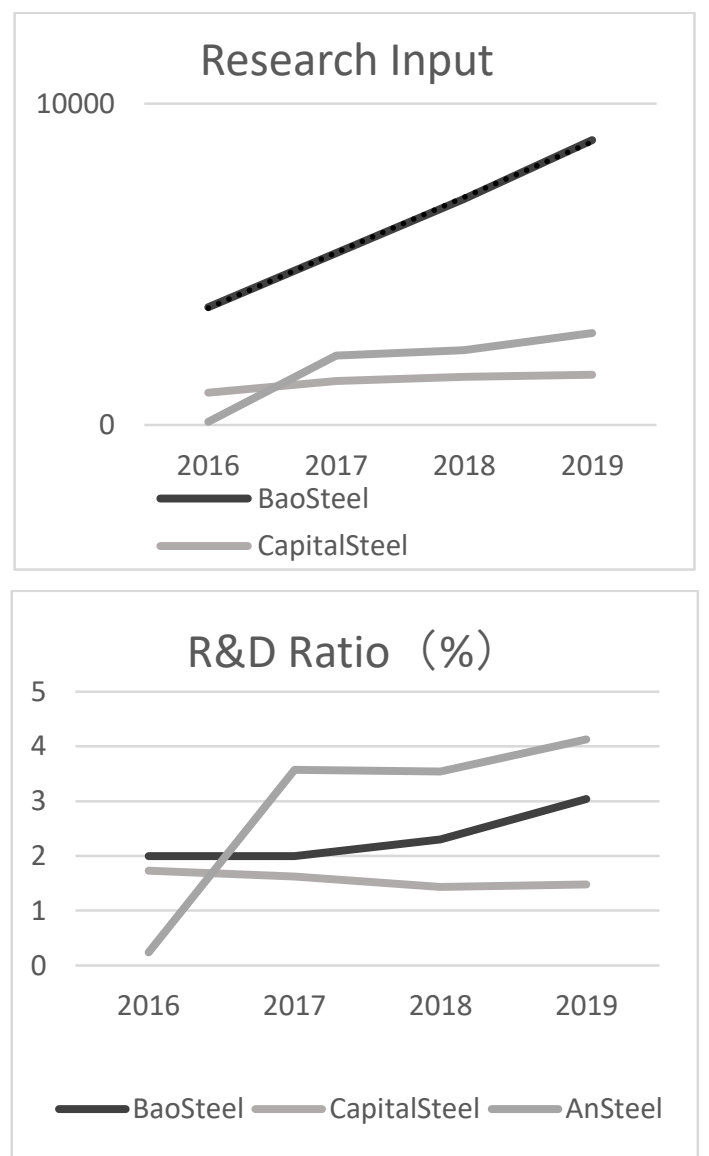

Figure 3 Research and development investment analysis

\subsection{Summary: SWOT analysis}

\subsection{1. $\quad$ Strengths}

As a leading enterprise in Chinese iron and steel industry, Baosteel has multiple advantages.

Brand effect to Baosteel has brought a steady stream of customers, good goodwill let Baosteel save a large amount of advertising costs.
The nature of Baosteel's large-scale state-owned enterprises has made them get a lot of profits in national policies. The speed of daily policy approval and the project implementation is fast. The national reform dividend is given priority, and the national subsidies can also be received in full and on time;

Baosteel's profitability is the best among domestic steel enterprises, which makes it more comfortable in technology research and development. Even though Capital steel's R \& D ratio exceeds Baosteel's, Baosteel's huge operating profit makes its $\mathrm{R} \& \mathrm{D}$ investment increase significantly even if its $\mathrm{R} \& \mathrm{D}$ ratio is only slightly increased, and continues to widen the gap with Ansteel and Capital steel, forming a benign mutual promotion between profit growth and scientific and technological level Circulation, profitability and R \& D capacity both expand the leading edge. ${ }^{[4]}$

The scale effect formed by the coordinated development of the four production bases based on their respective regional advantages is hard to match for domestic steel enterprises.

\subsubsection{Weakness}

Baosteel's internationalization started late and the available foreign market is small. Its international supply and marketing channels still need to be optimized;

Compared with Japanese and Korean steel enterprises, Baosteel's scientific research capacity still lags behind the world's top level;

Baosteel is highly dependent on foreign iron ore, but it has not yet established a subsidiary company for iron ore mining. The raw material procurement cost is high and the risk is high.

\subsubsection{Opportunity}

The report on the work of the government of the State Council in 2020, issued in May 2020, proposes to focus on supporting the construction of new infrastructure, new urbanization, transportation, water conservancy and other major projects. The implementation of the "two new and one heavy" construction means that the demand for steel will be greatly increased, and the iron and steel industry will usher in new development opportunities, which is great good news for Baosteel.

As the domestic epidemic situation has been comprehensively controlled, Chinese steel enterprises have taken the lead in recovering from the epidemic, while foreign steel enterprises are still troubled by the epidemic situation, so this is a good opportunity for Baosteel to reshuffle.

Chinese "The Belt and Road Initiative" policy has allowed more and more Chinese enterprises to go abroad. Chinese support from the state level has helped Baosteel 
win the list of foreign governments. Meanwhile, more and more Chinese enterprises are appearing in Baosteel's value chain, which is conducive to reducing costs and risks. ${ }^{[4]}$

\subsubsection{Threaten}

Protectionism and unilateralism are on the rise, and trade barriers have hindered Baosteel's progress in internationalization and fallen behind in the competition with other countries' steel products;

The epidemic has made the already uneasy international environment even more turbulent, with riots in the United States, continuous conflicts between India and China, and wars between Armenian and Azerbaijani. Baosteel's business environment is getting worse.

\section{BAOSTEEL'S STRATEGIC CHOICE: "1+5" STRATEGY}

Lower production cost and leading industry technology are the necessary conditions for high-quality development of enterprises; perfect supporting services, unmanned production and global supply are the future development trends of all enterprises.

\subsection{Multi manufacturing base management mode}

Multi manufacturing base management mode is the overall embodiment of Baosteel's enterprise mission. "High quality development" is inseparable from the use of regional advantages, but the relatively scattered location will bring certain difficulties to collaborative production. The four manufacturing bases, Baoshan in Shanghai, Qingshan in Wuhan, Dongshan in Zhanjiang and Meishan in Nanjing, are scattered and concentrated in Central China, East China and South China, and relatively concentrated in the Yangtze River Basin. They can form industrial clusters and scale effects, and can also take advantage of the location advantages of the three regions. With the internationalization of Baosteel step by step, new manufacturing bases will be built abroad in the future to lead the future steel manufacturing. ${ }^{[5]}$

\subsection{Cost revolution}

Cost revolution is the continuation of the management model of multiple manufacturing bases, promoting "high quality" with cost reduction, and leading "future" with global value chain.

Baosteel is not superior to its suppliers in terms of strength, especially under the difficulty of rising iron ore prices. It is not easy for Baosteel to achieve high-quality development through lower production costs. Therefore, Baosteel has made full efforts in procurement, manufacturing and sales. ${ }^{[5]}$ In procurement, they promote competitive procurement and take advantage of those with good quality and low price; establish subsidiaries overseas through acquisition, sole proprietorship and joint venture, establish a set of overseas supply chain system with high coordination from raw material procurement to transportation, implement global procurement and reduce raw material costs and logistics costs. In manufacturing, intelligent manufacturing is used to replace labor and reduce labor costs; waste steel is recycled by external enterprises to reduce disposal costs; steel manufacturing and processing subsidiaries are established in India, Indonesia and other places to reduce costs by taking advantage of location. In sales, the company strengthened the coordination between production and sales and reduced the storage costs of warehouses; with the help of the "service first" strategy, the company supported overseas trading subsidiaries around the world, reducing the cost of communication with customers.

\subsection{Leading technology}

Whether at present or in the future, leading technology is the greatest competitiveness of enterprises. In March 2020, Baosteel developed two new brands of antibacterial nickel saving austenitic stainless steel, which have good broad-spectrum antibacterial properties against common Escherichia coli and Staphylococcus aureus. The products have broad application prospects in kitchen utensils, medical and health care, home travel, household appliances, public facilities and other fields. In September, Baowu of China officially opened hydrogen metallurgy. To reduce the emission of greenhouse gases in iron and steel metallurgy process, hydrogen is gradually replaced by carbon. ${ }^{[6]}$

However, Baosteel did not stop its R\&D and developed antibacterial stainless steel products, which demonstrated the R\&D capability and social responsibility of the enterprise, and embodied the enterprise mission of "being a demonstrator of highquality development of the iron and steel industry". Due to the pressure of energy conservation and emission reduction, Baosteel chose to reconfigure hydrogen metallurgy in the face of the dilemma of having to eliminate the old production equipment. The equipment conforms to the trend of clean energy metallurgy and achieves the mission of "being the leader of steel in the future".

\subsection{Service first}

Baosteel strengthened the pre-sale and after-sales service, built a technical inquiry system, quickly responded to the user's needs, and simultaneously planned the hierarchical management mechanism of user's demand, so as to realize the rapid landing of customer's demand to the manufacturing end. Coordinate the regional technical service resources and provide close 
service to users through the company's customer representative. They have continued to promote the construction of service network and capacity layout, and enhance the international operation ability. They have set up 141 marketing service outlets around the world, formed 4 overseas regional headquarters, 3 overseas steel processing service centers and 16 laser tailor welding plants. The annual customer satisfaction in 2019 was $92.5 \%$

In the plight of reduced steel market demand, Baosteel has left a good impression on customers through high-quality supporting services, established a good reputation, played a demonstration role for other steel enterprises, won more repeat customers for the future, and realized its mission.

\subsection{Smart manufacturing}

Smart manufacturing relies on technology leadership, which in turn promotes cost change, which is a prerequisite for "being the leader of steel in the future". In the future, artificial intelligence will certainly replace a large number of manual labor. Baosteel focuses on "less human, unmanned and centralized control". [5][7] According to the information disclosed in the 2019 report, Baosteel has launched 112 intelligent equipment transformation projects and 1,084 people have the opportunity to get rid of heavy manual labor and form a batch of intelligent manufacturing achievements such as "one key steelmaking" and "unmanned heavy loaded frame car control and scheduling technology", and improve the intelligent manufacturing capacity by using big data, Internet of things and artificial intelligence technology. It can be predicted that with the promotion of Baosteel's unmanned production, the labor cost will continue to decline.

\subsection{Urban steel plant}

The strategy of "City steel plant" is based on the strategy of "leading technology" and "smart manufacturing", and is the best comment on the "model of high-quality development" in the corporate mission. First of all, Chinese energy conservation and emission reduction strategy has put forward high requirements for Baosteel's clean technology. If the pollutant emissions exceed the standard, Baosteel will face a huge fine. Baosteel has to invest a large amount of money to purchase new equipment and develop new production and clean technology, which is a difficulty faced by Baosteel. Baosteel, through promoting regional unorganized dust control, building ecological greening in the plant area, and cooperating in the treatment of urban solid waste resources, has found new opportunities in the difficult situation. In February 2019, Baosteel obtained the first business license for hazardous wastes from social paint barrels and the business license for hazardous wastes incineration in the steel industry. Baosteel enjoys the income reduction policy for comprehensive utilization of resources and the total credit of special equipment investment of 40 million, which relieve the tax burden of the enterprise.

Secondly, excellent enterprises are bound to take on social responsibilities and devote themselves to public welfare and charity undertakings and community construction. ${ }^{[7]}$ In 2019, Baosteel invested 4800 million yuan in targeted poverty alleviation, far higher than the 180 million yuan in Ansteel, playing a demonstration role. Huge amount of poverty alleviation funds will bring great pressure on the cash flow of Baosteel, but it is also an opportunity for Baosteel. Baosteel's targeted poverty alleviation strategy is to "increase the input of assistance according to the proportion of 5:4:1 for the whole village promotion, industrial development, education and training". As a result, Baosteel has become a well-known brand and will inevitably choose Baosteel after the development of poverty-stricken villages. Those newly developed industries often need some low-end steel products. Baosteel has virtually expanded its sales and also emptied its inventory, which is a good thing for Baosteel, which has a low inventory turnover rate.

Through the strategy of "urban steel plant", Baosteel not only made contributions to environmental protection and social construction, but also enhanced its own value, playing an exemplary role in Chinese steel industry and realizing the mission of "being a demonstrator of highquality development of the steel industry". ${ }^{[7]}$

\section{CONCLUSION}

In the difficult environment, Baosteel has worked out a reasonable enterprise strategy, withstood the pressure, and continuously carried out the established mission of the enterprise, which provided valuable and referential experience to the domestic counterparts. Moreover, Baosteel still has something better to do, such as improving the company's operating capacity, speeding up the capital turnover, increasing the emphasis on talents, and putting the talent plan into the company's strategy. In the future, Baosteel will face opportunities as same as difficulties. In the context of the continuous improvement of Chinese comprehensive national strength, Baosteel is expected to continue its good development momentum and fulfill its mission.

\section{REFERENCES}

[1] Gao Yi. Empirical Study on international steel industry transfer and influencing factors [D]. Fudan University, 2007

[2] Rui,Jin.(2006)On the Establishment of Financial Analysis Index System in Large Enterprise Groups[J].On Economic Problems,09:42-43. 
[3] Mi Jianwei. Forecast and suggestions on the development of Chinese iron and steel industry in the next five years $[\mathrm{J}]$. China Economic and trade guide, 2011, (12): 70-71 DOI:10.3969/j.issn.10079777.2011.12.034.

[4] Pian Feng, Luan Weixin, Li Dan, et al. Research on industrial concentration of Chinese iron and steel industry $[\mathrm{J}]$. Exploration of economic problems, 2014, (10): 70-75 DOI:10.3969/j.issn.10062912.2014.10.011.

[5] Li Huan, Mo Xin Yue. Application of intelligent manufacturing technology in Chinese steel industry in the era of Internet plus [J]. world science and technology research and development, 2017,39 (1): 62-67.

[6] Zhao Wenbao, Li Ying. Study on "going out" to solve the problem of overcapacity in iron and steel industry $[\mathrm{J}]$. Journal of Hebei University of economics and trade, 2018,39 (2): 78-86

[7] Li Xin, Yang Liyan, Mu Xianzhong, et al. Path mechanism of high quality development of iron and steel industry promoted by ecological environmental protection [J]. Environmental protection, 2020,48 (3): 90-95 